\title{
Read Depth
}

National Cancer Institute

\section{Source}

National Cancer Institute. Read Depth. NCI Thesaurus. Code C155320.

The number of times a particular locus (site, nucleotide, amplicon, region) was sequenced. 